4. Tita A, Landon MB, Spong CY, Lai Y, Leveno KJ, Varner MW, et al. Timing of elective repeat cesarean delivery at term and neonatal outcomes. $\mathrm{N}$ Engl $\mathrm{J}$ Med. 2009;360:111-20.
5. Mackay DF, Smith GC, Dobbie R, Pell JP. Gestational age at delivery and special educational need: retrospective cohort study of 407,503 school children. PLoS Med. 2010; 7: e1000289.

\section{Hypocalcemia and Tachycardia Induced Cardiomyopathy}

Kourti, et al. [1] have highlighted important aspects of tachycardia induced cardiomyopathy and cardiogenic shock in their letter. We wish to share our experience in handling a child with tachycardia induced cardiomyopathy and cardiogenic shock resulting from hypocalcemia.

We describe a 4-month-old infant, who presented to pediatric emergency in cardiogenic shock and supraventricular tachycardia. He presented with cold and mottled peripheries, cyanosed and in hypotensive shock. He was given a saline bolus at $10 \mathrm{~mL} / \mathrm{kg}$ over 30 minutes and started on IV adrenaline. ECG revealed SVT which was reverted to normal rhythm with the use of second dose of IV adenosine at $0.2 \mathrm{mg} / \mathrm{kg}$. Transthoracic echocardiography revealed a dilated left ventricle with hypokinesia with markedly reduced left ventricular ejection fraction of $22 \%$, without any congenital cardiac defects. Troponin $\mathrm{T}$ was negative by card test and serum CPK- MB levels were also normal. His ionized calcium was low $(0.2 \mathrm{mmol} / \mathrm{L})$. Serum magnesium levels were normal. Child was started on Inotropes (Milrinone and dobutamine) and calcium chloride was given to correct his hypocalcemia. Adrenaline was tapered off followed by dobutamine and milrinone. No antiarrhythmics were given as maintenance therapy. His calcium levels improved to $1.1 \mathrm{mmol} / \mathrm{L}$ and gradually his LVEF improved to $60 \%$. At discharge, child was asymptomatic and hemodynamically stable.

In managing these patients, electrolytes like calcium and magnesium are important part of work-up, apart from those described by the authors. Both hypocalcemia and hypomagnesemia have been reported as causes of arrhythmias in children as well adults [2,3]. Since this child had two such episodes, he also needs to undergo electrophysiological study to look for any conduction pathway defect, which is rare but a important cause to look for in patients with repeated arrhythmias.

AtUl Jindal Fortis Hospital, Jaipur, Rajasthan, India. dratuljindal@gmail.com

\section{REFERENCES}

1. Kourti M, Sdougka M. Tachycardia-induced cardiomyopathy presenting with cardiogenic shock. Indian Pediatr. 2012;49:499-500.

2. Machado JD, Suen VM, Chueire FB, Marchini JF, Marchini JS. Refeeding syndrome, an undiagnosed and forgotten potentially fatal condition. BMJ Case Rep. 2009;2009.

3. Klevay LM, Milne DB. Low dietary magnesium increases supraventricular ectopy. Am J Clin Nutr. 2002;75:550-4.

4. Leibovitz A, Golic A, Brauman A, Gilboa Y. Supraventricular tachycardia due to hypocalcemia. Harefuah. 1980;99:174-5.

\section{Specific Learning Disability - The Road to Disability Act}

We would like to thank Dr Unni [1] for highlighting his concerns regarding specific learning disability (SLD) and bringing such an important yet not so common issue into limelight. The greatest hurdle lies in identifying these children so that only the deserving child gets the benefit if SLD forms part of Disability Act. The developed countries were early to recognize and quick to act on such issues. India is a vast multilingual country. It is not possible to apply any Western tool directly to our children due to different social and educational structure and the norms will vary. The SLD battery test developed and validated by National Institute of Mental Health and Neurosciences (NIMHANS) [2], does not have proper norms. Moreover the tool does not cover the cognitive aspect. We need a foolproof tool to find the prevalence of SLD in public and private schools. First generation learners should be excluded or else the prevalence will be high as environment plays an important factor in the development of the child.

For disability benefit or relaxation in education board norms, who will certify children with SLD? This 